\title{
Community Health Workers' Attitude Towards People with Mental Illness: Potential Challenge of Maternal Mental Health Services in a Selected Health Centre, Ruhengeri Hospital in Rwanda
}

Vedaste Baziga $^{1 *}$, Augustin Gasovya ${ }^{1}$, Fauste Uwingabire ${ }^{2}$

${ }^{1}$ Department of Mental Health Nursing, School of Nursing and Midwifery, College of Medicine and Health Sciences, University of Rwanda ${ }^{2}$ Departments of Neonatology,School of Nursing and Midwifery, College of Medicine and Health Sciences, University of Rwanda

*Corresponding author: VedasteBaziga. Department of Mental Health Nursing, College of Medicine and Health Sciences, University of Rwanda, Remera Campus , KG 11 Ave, 47 Kigali, Rwanda. Email: vedastebaziga2@gmail.com

\begin{abstract}
Introduction

Integration of mental health services into non psychiatric health care facilities from community level was recommended by the world health organization (WHO) in 1984 to improve the quality of mental health services provided to the local population. Community Health Workers (CHWs) have an important role to play for the implementation of WHO recommendation of integration especially at the community level. Research objectives were to: Describe attitude among CHW stowards people with a mental illness and explore relationships between socio-demographic variables and CHWs' attitude towards people with mental illness in Muhoza health center/Ruhengeri hospital in Rwanda. Methods

In this study, a quantitative descriptive cross-sectional design was used to conduct a research among CHWs operating under Muhoza health centre/ Ruhengeri hospital in Rwanda. A selfreport questionnaire was used to collect data on a sample of 138. Questionnaire consisted of sociodemographic variables and two sections that include level of contact (LOC) and the Community Attitude towards Mental Illness-Swedish version (CAMI-S). The statistical package for social sciences (SPSS) version 22 was used to analyze data.

Results

Findings showed negative attitude among community health workers in regards to people with mental illness (MI). The participants' total score on the CAMI-S was ranging between $25 \%$ and $87 \%$. This study revealed that participants with lower level of education and less experienced as CHWs reflected higher negative attitude in regards of people with mental illness than participants with higher level education and more experienced. Also, results from this study indicated that increase in LOC correlates with decrease in fear and avoidance towards people with mental illness.

\section{Conclusion}

Community health workers in a selected Health Centre/ Ruhengeri Hospital, in Rwanda hold negative attitudes towards people mentally ill. Also, there is association between negative stereotypes towards people mentally ill and the level of education and experience. Familiarity has a mediating effect on negative attitudes hold by community health workers in regards to people mentally ill.

Rwanda J Med Health Sci 2019;2(3):220-229.
\end{abstract}

\section{Keywords: Community health workers, mental illness, health centre, negative attitude.}

\section{Introduction}

Mental illnesses (MIs) are psychiatric clinical conditions characterized by a significant behavioural and psychological pattern associated with distress and impairment in different areas of functioning. The American psychiatric association stated that persons with mental illness can be disconnected with the reality (example, psychotic disorders) and others not (example; personality disorders, psychosomatic disorders, anxiety disorders).[1] In addition, mental illnesses are categorised into three levels according to their severity (mild, moderate and severe). For example literature differentiates major depression from minor depression. [1] Mental illnesses are common and affecting countries worldwide and represent $13 \%$ and are expected to rise up to $15 \%$ by the year $2020[2,3]$ MIs are among four leading causes of disability whereby $30 \%$ of disability cases were reported to be related to mental illness.[2,3] In 1984, WHO recommended worldwide countries to integrate mental health services, to overcome problems associated with mental health issues that are affecting 
the population locally and globally. The process of such integration was suggested to start from community based health care facilities up to referral health care facilities in 2005.[4] The Rwandan Government was highly interested by such integration as long as Rwandan citizens faced a tragedy of Genocide against Tutsis in 1994. The genocide against Tutsis significantly affected the Rwandan population and led to psychological traumatism that was influencing mental health services in Rwanda.[5,6] the Rwandan Ministry of Health started to integrate mental healthcare from the community to referral level of health care settings since 2005.[6,7] For its implementation, the Rwandan Ministry of Health suggests that such integration at community level, relies on Community Health Workers who are involved in promotive, preventive, curative and rehabilitation activities for the local population mental illness.[7,5] The CHWs package of activities includes health related services such as sensitization and health education for prevention of mental illness and mental health promotion. $[5,8,9]$ The CHWs are not considered as health care professionals but they work jointly with nurses and other health professionals from health centres. CHWs are trained, supervised and supported by the Health Centre. $\mathrm{CHWs}$ are also involved in some activities planned and implemented by the Health Centre at the community level in favour of maternal and child health. $[5,8,10]$ Maternal health includes maternal mental health during pregnancy, during and after delivery.

Current literature suggests that having integrated mental health services in different heath care facilities would reduce negative attitude held by the public towards mental illness. However, in some countries like Zambia, Nigeria, Uganda and Ghana it has been shown that professionals have negative attitude in regards to people with mental illness. This issue of negative attitude in regards to people with mental illness was found among health professionals in rural District (Uganda) and in primary Health Care (Zambia).[10-12]

CHWs as a part of the general population may also reflect negative attitude towards people with mental illness. $[13,14]$ However, there are few known local research data regarding stigma associated with mental illness among the general population and health professionals particularly including CHWs. Similar studies were conducted among nurses and student in school of nursing, who are argued to be part of the implementation of integrated care. $[15,16]$ There is no doubt that the issue of negative attitude and stigma in general is a potential obstacle to the mental health services integration into different levels of health care settings.

This study aims to describe attitudes in regards to persons with mental illness among CHWs operating in the catchment area of Muhoza Health Centre in Ruhengeri hospital in Rwanda. This is aiming at informing anti stigma initiatives to reduce stigma amongst CHWs. The CHWs are argued to have an important role in Rwandan health care system regarding maternal and child health.

\section{Methods}

\section{Design}

The current study was conducted using quantitative, descriptive and non-experimental design that makes use of a self-report questionnaire to facilitate an audit of the attitude of community health workers with regard to mental illness. The design facilitates the researcher's ability to access and describe attitude of community health workers towards persons with mental illness in Muhoza health centre/ Ruhengeri hospital in Rwanda.

\section{Study setting and participants}

The study has been conducted in Muhoza health centre/ Ruhengeri Hospital in Rwanda that is a community health care facility. The target Health Centre was conveniently sampled because of its location that was near the researcher work place when he was supervising students during community clinical placement. Also, the researcher had established a relationship with the head of Muhoza health Centre.[17] Muhoza Health Centre provides comprehensive and primary health careincluding outpatient consultation, maternity, antenatal care, immunization, Voluntary Counselling and Testing, preventing mother to child transmission of human immunodeficiency virus (HIV). Also, health centre supervises and coordinates activities provided by $\mathrm{CHWs}$ and Health posts operating under its responsibility. In addition, mental health services are integrated into the package of activities of Health Centre (basic mental health services) according to WHO suggestions about the essential medication.[18] Muhoza health centre has 22 nurses providing health services at health centre setting and organizing home visits in the community setting where community health workers are found and work from.

All Community Health Workers (CHWs) operating in the catchment area of Muhoza health Centre and who deliver different health services to the local population, were included in this study. The catchment area of Muhoza health centre includes 26 villages from Muhoza sector, 12 villages from Musanze sector and 11 villages from Cyuve sector. Villages served by Muhoza Health Centre make a total of 49 villages that have 147 community health workers as each village has 3 community health workers. Villages and community health workers were not sampled to obtain sufficient numbers for statistical power in the data analysis that necessitated at least 100 participants. Of 147 community health workers operating under Muhoza health centre, 138 community health workers were available and accepted to participate in this study which allowed achieving a response rate of $93.8 \%$.

\section{Instruments}

To conduct this research, the researcher decided to use self-report questionnaire to collect data on attitude among community health workers in regards to persons with mental illness. This tool has been adopted from the original level of contact scale (LOC) as developed by Corrigan and colleagues in 2001 and the original 
Community Attitude towards Mental Illness Swedish version as developed by Högberg and the researchers' team in 2008 in Sweden. The self-reported questionnaire was composed of three sections. First section includes socio-demographic variables (age, gender, experience and level of education). In this study socio-demographic variables are taken as independent variables

The second section is about familiarity (level of contact) as developed by Corrigan \& his research group in 2001 . [19] The level of contact consists of twelve levels ranging from "Never observed a person with mental illness" to "I have mental illness" and was considered as dependant variable. The level of contact scale was developed to measure the extent of participants' familiarity towards persons with mental illness. The tool was previously used by different researchers internationally and locally. For example, in Sweden by Martensson and colleagues (2009), in Nigeria by James and the research team (2012), Adewayu and Maknjuola (2008) and in South Africa by Smith and Middleton (2010).[20-22] Holmes and Colleagues reported the reliability of LOC to have inter item of 0.83.[23]

The third section was about Community Attitude towards Mental Illness Swedish version (CAMI-S). This section has three subscales which make a total of 20 items: open minded and pro-integration subscale (9 items); fear and avoidance subscale (6 items); and community mental health ideology subscale (5 items). The Community Attitude towards Mental Illness Swedish version (CAMI-S) [24] has been reported to have good reliability, on the 20 items (0.903) generally. In this study the subscales and total score on the Community Attitude towards Mental Illness Swedish version were considered as dependent variables.

Both level of contact scale, and community attitude towards Mental Illness- Swedish version were in English and the translation was done from English to Kinyarwanda by a translation expert person working at the CMHS centre of language enhancement. The translation was done due to the fact that CHWs do not have ability to express themselves in English, thus local language is highly recommended to be used.

\section{Data collection procedures}

A meeting was held with the Head of Muhoza health centre and in charge of community health in Muhoza health centre to discuss about the process of data collection. The head of Muhoza health centre was contacted before community health workers because the health centre supervises and coordinates all community health workers activities.

The researcher and the head of Muhoza health centre agreed on schedule according to the working hours especially when community health workers were invited at Muhoza health centre for any activities; such as the meetings. Implied consent was used by the researcher for the participants by giving back the self-report questionnaire to the researcher. The researcher took this opportunity to collect data but without disturbing scheduled activities as appointment for collecting data was always placed at the end of their activities at Muhoza health centre. Also, the researcher connected telephonically with the executive secretaries of cells served by Muhoza health centre (Muhoza sector: 4 cells, Musanze sector: 2 cells and Cyuve sector: 2 cells) to facilitate meeting with community health workers of respective cells, who did not meet with the researcher at Musanze health centre. The researcher collected data from available participants and Information sheets were distributed to available community health workers who accepted to participate in the current study. Participants were given the opportunity to ask questions before starting the data collection. Collected data was kept in a sealed envelope provided by the researcher.

\section{Analysis of data}

The statistical package of social sciences (SPSS), Version 22 was used to analyse data. On section two that contained 12 statements (LOC), the single highest score was recorded because the participants were asked to tick on each statement applicable to them. On section three (CAMI-S) reverse scoring was used on the following items $4,5,6,10,11,12,13,17$ and 20 . The remaining items $(1,2,3,7,8,9,14,15,16,18$ and 19) were not reversed. The reverse scoring was done because the statements mentioned above were expressing negative attitude towards persons with mental illness while scale starts by less stigmatizing attitude to more stigmatizing attitude (strongly agreeing with the statement (1) agreeing with the statement (2) neutral (3), disagreeing with the statement (4) and strongly disagreeing with the statement (5). This is why the reverse was performed on the mentioned statements and resulted in the following scoring: Strongly agreeing with the statement (5) agreeing with the statement (4) neutral (3), disagreeing with the statement (2) and strongly disagreeing with the statement (1).

Regarding descriptive statistics, the range (minimum and maximum), mode (most commonly occurring score), median (the middle score when the score are ranked from smallest to largest and sometimes known as the midpoint), skewness statistic and standard error of skewness statistic (values that provide an indication of the symmetry of distribution), and quartiles, were used. Percentages, proportions, range, mean and standard deviation of subscales and total score on the community attitude towards mental illness- Sweden version, were computed. An independent $\mathrm{t}$-test was used to compare the mean score of CAMI-S subscale for males and females (association). One way between groups analysis of variance (Post Hoc Tests) was conducted to test relationship between independent (age, level of education and experience) variables and CAMI-S subscales and total score.[25] Correlation was tested by using the Spearman's rho correlation coefficient test and the correlation was tested between level of contact (LOC) and CAMI-S subscales and total score.[25]

\section{Ethical Considerations}

Before starting the data collection, the ethical clearance 
has been offered by the CMHS institutional review board (No 020/CMHS/IRB/2016). Also, a permission to conduct a research was given by the District of Musanze (No 0662/07.04.03) as an administrative structure that supervises all activities of health institutions including Muhoza health centre. Implied consent was used to reduce social desirability bias which is argued to influence participants' responses. The choice to use implied consent was aiming at boosting the issue of anonymity and confidentiality. [17] Here, the implied consent was considered by the researcher as consent to participate in research on certain actions of the participant, such as returning a completed questionnaire.[17,26] In additionCHWs are not vulnerable persons and there were not noticed any risks. The study was a low risk research as long as it was not argued to harm the participants. There was no incentives that could influence participant's responses. [17,26]

\section{Results}

\section{Study participants characteristics}

The total number of participants was $(n=138)$ and the majority included female participants $(\mathrm{n}=80 ; 58 \%)$ and minority of male participants ( $n=48 ; 42 \%)$. Distribution of participants according to their age was as follows; age $18-21(\mathrm{n}=32 ; 58 \%) ; 22-25(\mathrm{n}=52 ; 47.7 \%) ; 26-30$ : $(\mathrm{n}=23$; $16.7 \%)$ and $<30$ : $(\mathrm{n}=5 ; 3.6 \%)$. Regarding the education level, data was distributed as follows; participants without completing primary school $(\mathrm{n}=32 ; 23.2 \%)$, those who completed primary school $(\mathrm{n}=102 ; 73.9 \%)$, O' level (secondary school $(\mathrm{n}=4 ; 2.9 \%)$ and University level $(\mathrm{n}=0$; $0 \%$ ). Lastly, the majority of participants were experienced between $3-5$ years of experience $(n=50 ; 36.2 \%)$; followed by less than 1year $(\mathrm{n}=39 ; 28.3 \%) ;<5$ years $(\mathrm{n}=25 ; 18.1 \%)$ and $1-3$ years of experience $(n=24 ; 17.4 \%)$.

\section{Table 1. Sociodemographic data distribution}

\begin{tabular}{lrr}
\hline Sociodemographic variables & Frequency & Percentage \\
\hline Gender of participants & & \\
Female & 80 & $58 \%$ \\
Male & 58 & $42 \%$ \\
Total & $\mathbf{3 8}$ & $\mathbf{1 0 0 \%}$ \\
\hline Age of participants (in years) & & \\
$18-21$ & 58 & $32 \%$ \\
$22-25$ & 52 & $47.7 \%$ \\
$26-30$ & 23 & $16.7 \%$ \\
$<30$ & 5 & $3.6 \%$ \\
Total & $\mathbf{3 8}$ & $\mathbf{1 0 0 \%}$ \\
\hline Experience of participants (in years) & & \\
$0-1$ & 39 & $28.3 \%$ \\
$1-3$ & 24 & $17.4 \%$ \\
$3-5$ & 50 & $36.2 \%$ \\
$<5$ & 25 & $18.1 \%$ \\
Total & $\mathbf{3 3}$ & $\mathbf{1 3 8}$ \\
Level of education of participants & & \\
Primary not completed & 32 & $23.2 \%$ \\
Primary & 102 & $73.9 \%$ \\
Secondary & 4 & $2.9 \%$ \\
University & 0 & $0 \%$ \\
Total & 138 & $\mathbf{1 0 0} \%$ \\
\hline
\end{tabular}

\section{Level of contact (LOC)}

Data from the LOC included the participants' highest score only, with a single score being recorded to represent participants' greatest level of intimacy from 12 situations with a person with a mental illness.

The level of contact among the participants was measured by the LOC scale as described in the section of research instruments. The study participants level of contact was ranged between "observed a person with mental illness in passing" $(0.6 \%)$ and "I have mental illness" $(8 \%)$. The highest score on the LOC was considered to be reported and the participants were asked to tick on every statement applicable to them. The highest score on the LOC was considered by the researcher to be included into the calculation of percentages in regards to LOC with persons with mental illness. The level 7 was the highest score achieved by participants on the LOC “providing services to person with severe mental illness"(19.6\%). This highest score is not surprising as long as community health workers provide promotion, preventive, and rehabilitation services to the population within the community including persons with mental illness. [5]

\section{Participants' attitude towards persons with mental illness}

As displayed in Table 2, findings were expressed in percentages to show the level of agreement or disagreement by participants on each statement. Also, findings from this study confirm that the participants reflected negative attitude in regards to mental illness on all items of the CAMI-S. This negative attitude among community health workers was evidenced by the fact that some participants were in certain disagreement with the statements. However, Table 3 indicates that negative attitude was less prevalent on the following items than others: Item 16: The best therapy for many mental patients is to be part of a normal community with $18.8 \%$ of participants who disagreed and $67.8 \%$ of participants who agreed with the statement. Also, participants reflected more positive attitude towards persons with mental illness: item 18: As far as possible, mental health services should be provided through community-based facilities (68.8\%) and item 8: We need to adopt a far more tolerant attitude towards the mentally ill in our society (68.8\%).

Table 2 shows that negative attitude was more prevalent in the item 12: It is frightening to think of persons with mental problems living in residential neighborboods whereby only a half $(49.3 \%)$ of participants disagreed with the statement.

The findings from the current study suggest contradictions amongst participants regarding different items. Significant contradictions were revealed on the item 19: No one has the right to exclude the mentally ill from their neighborhood and item 8 "We need to adopt a far more tolerant attitude towards the mentally ill in our society" compared to the item 12 "it is frightening to think of persons with mental 
problems living in residential neighbourboods "and item 5: Having mental patients living within residential neighborhoods might be a good therapy, but the risks to the residents are too great. The study participants were for the opinion that community members need to adopt far more tolerant attitude persons with a mental illness and mental health services being provided through the communitybased facilities. While at the same time the participants believe that it is frightening to have persons with mental problems living in residential neighborhoods. In addition, participants support the idea of providing mental health services in community-based health care facilities, while they consider residents to have a great risk when they are living with persons mentally ill.
Also, the current study revealed neutral responses on all items for the Community Attitude towards Mental Illness- Swedish version. However, on item 5: Having mental patients living within residential neighborboods might be a good therapy, but the risks to the residents are too great, participants reflected more neutral responses than positive attitude whereby $26.8 \%$ agreed; and $31.9 \%$ neutral responses. It is possible that the extent of neutral responses within this study is also a reflection of ambivalence thus suggesting that participants preferred to take a neutral position rather than exhibiting negative attitudes towards people with a mental illness.

\section{Table 2. Community Attitude towards Mental Illness- Swedish version}

\section{Open minded and pro integration subscale}

1. Residents should accept the location of mental health facilities in their neighbourhood $37 \%$ to serve the needs of the local community

2. Most persons who were once patients in a mental hospital can be trusted as babysitters $23.9 \%$

3. Locating mental health services in residential neighbourhoods does not endanger local residents

4. Mental health facilities should be kept out of residential neighbourhoods

$21.7 \%$

$23.2 \%$

5. Having mental patients living within residential neighbourhoods might be a good therapy, but the risks to the residents are too great

6. Local residents have good reason to resist the location of mental health services in their neighbourhood

7. Mental illness is an illness like any other

8. We need to adopt a far more tolerant attitude towards the mentally ill in our society

9. The mentally ill are far less of a danger than most persons suppose

Fear and avoidance subscale

10. It is best to avoid anyone who has mental problems

11. I would not want to live next door to someone who has been mentally ill

12. It is frightening to think of persons with mental problems living in residential neighbourhoods

13. The best way to handle the mentally ill is to keep them behind locked doors

14. Residents have nothing to fear from persons coming into their neighbourhood to obtain mental health services

\section{Community mental health ideology subscale}

15. Less emphasis should be placed on protecting the public from the mentally ill

16. The best therapy for many mental patients is to be part of a normal community

17. The mentally ill should not be treated as outcasts of society

18. As far as possible, mental health services should be provided through communitybased facilities

19. No one has the right to exclude the mentally ill from their neighbourhood

20. The mentally ill should be isolated from the rest of the community

$23.2 \%$

$18.8 \%$

$26.1 \%$

$23.2 \%$

$\begin{array}{llll}23.2 \% & 13.8 \% & 10.9 \% & 15.2 \% \\ 23.2 \% & 15.2 \% & 29.2 \% & 8.0 \% \\ 29.7 \% & 18.1 \% & 26.1 \% & 4.3 \% \\ 23.9 \% & 9.4 \% & 31.9 \% & 11.6 \% \\ 17.4 \% & 31.9 \% & 31.9 \% & 9.4 \% \\ 20.3 \% & 23.9 \% & 23.9 \% & 7.2 \% \\ 32.6 \% & 8.7 \% & 17.4 \% & 7.2 \% \\ 26.8 \% & 11.6 \% & 9.4 \% & 10.1 \% \\ 37 \% & 10.1 \% & 23.9 \% & 4.3 \%\end{array}$

$26.8 \% \quad 13 \%$

$19.6 \%$

$16.7 \%$

$24.6 \% \quad 17.4 \%$

$29 \%$

$10.1 \%$

$8.7 \% \quad 13.3 \% \quad 8.7 \%$

$29 \%$

$20.3 \%$

$23.9 \% \quad 13 \%$

$18.8 \%$

$18.1 \%$

$34.8 \% \quad 17.4 \%$

$17.4 \%$

$7.2 \%$

$\begin{array}{lllll}16.7 \% & 28.3 \% & 18.8 \% & 25.4 \% & 10.9 \% \\ 27.5 \% & 41.3 \% & 12.3 \% & 9.4 \% & 9.4 \% \\ 41.3 \% & 26.1 \% & 8.0 \% & 8.7 \% & 15.9 \% \\ 34.8 \% & 26.1 \% & 15.2 \% & 15.2 \% & 8.7 \% \\ 41.3 \% & 27.5 \% & 9.4 \% & 10.9 \% & 10.9 \% \\ 41.3 \% & 13.8 \% & 10.9 \% & 15.9 \% & 18.1 \%\end{array}$

Table 3 displays subscales and total scores achieved on the CAMI-S. Measures of central tendency (mean, standard deviation) and distribution indicated more negative attitude towards mental illness on subscale 2 "fear and avoidance" 
(Mean=58.83; Std. deviation=16.082) than subscale 1 "Open minded and pro integration" (Mean=52.13; Std. deviation=17.365) and subscale 3 "Community mental health ideology" (Mean=47.16; Std. deviation=21.257). Findings from this study indicated that the extent of negative attitude in regards of mental illness between fear and avoidance subscale, open minded and pro integration subscale and Community mental health ideology subscale is almost similar.

The total scores achieved on the CAMI-S reflected a slightly skewed distribution and this skewness, is influenced by fear and avoidance subscale.

Table 3. Results of subscales and total score on Community attitude towards Mental illness Swedish version

\begin{tabular}{|c|c|c|c|c|c|}
\hline & & $\begin{array}{l}\text { Open minded and pro } \\
\text { integration }\end{array}$ & Fear and avoidance & $\begin{array}{l}\text { Community mental } \\
\text { health ideology }\end{array}$ & Total score \\
\hline \multirow[t]{2}{*}{$\mathbf{N}$} & Valid & 138 & 138 & 138 & 138 \\
\hline & Missing & 0 & 0 & 0 & 0 \\
\hline Mean & & 52.13 & 58.83 & 47.16 & 52.28 \\
\hline Std. Deviation & & 17.365 & 16.082 & 21.257 & 15.546 \\
\hline Skewness & & .198 & .059 & .669 & .353 \\
\hline Minimum & & 20 & 23 & 20 & 25 \\
\hline Maximum & & 91 & 87 & 100 & 87 \\
\hline
\end{tabular}

\section{Associations between socio-demographic variables and CAMI-S subscales and total score and correlations between the level of contact and CAMI- S subscales and total score}

Prior to perform any statistical tests, percentages, proportions, mean and standard deviation on CAMI-S subscales and total score were computed. Associations between socio-demographic variables and the CAMI-S subscales and total score, were tested and only significant associations were reported.[25] An independent samples t-test was used to compare the mean score of CAMI-S subscales and total score for males and females.[25] The significant difference was considered when the significance level of Levine's tests is $p=.05$ or less. Findings from this study revealed no significant difference on CAMI-S subscales and total scores for female and male participants.

Also, a one way between groups analysis of variance (Post Hoc Tests) was conducted to explore relationship between independent variables (age, experience and the level of education) and CAMI-S subscales and total score. Comparison of mean scores of CAMI-S subscales for participants groups was computed. These participants groups include; age groups (group 1: 18-21 years, group 2: 22-25 years, group 3: 26-30 years and group 4: 31 years and above), participants experience groups (group1: less than 1 year, group 2: 1-3 years, group 3: 4-5 years and group 4: above 5 years) and participant level of education groups (group 1: not completed primary school, group 2: completed primary school, group 3: secondary school). The statistical significance was considered if the significance value is less than or equal to .05.[25]

The Post Hoc Tests revealed no statistically significant difference in CAMI-S subscales and total scores for four participant age groups. However, a statistically significant difference in CAMI-S subscales and total score for four participants level of education groups was found Open minded and pro integration ( $\mathrm{F}=18.642 ; p=.000)$; fear and avoidance $(\mathrm{F}=10.865 ; p=.000)$; community mental health ideology ( $\mathrm{F}=6.935 ; p=.001)$; total score $(\mathrm{F}=17.332$; $\mathrm{p}=.000)$. In addition, the significant difference was confirmed by measures of central tendencies (mean and standard deviation as displayed in Table 4.

The mean and standard deviation showed that both participants who completed primary school and secondary school recorded lowest scores, with participants who did not completed primary school recoding the highest score on two subscales (subscale 1; open minded and pro integration and subscale 3; community mental health ideology) and the total score. The findings indicate that participants who completed primary school and secondary school reflected less negative attitude towards persons with mental illness than participants who did not completed primary school on CAMI-S subscales 1 and 2 and the total score. However, in regards to fear and avoidance subscale, the mean and standard deviation showed that participants who completed secondary school reflected less negative attitude towards mental illness than the two remaining groups.

Finally, the Post Hoc Tests revealed statistically significant difference in two CAMI-S subscales (subscale 2; fear and avoidance and subscale 3; community mental health ideology) for four participants' experience categories groups (group 1: less than year, group 2: 1-3 years, group 3: $4-5$ years and group 4: above 5 years). Fear and avoidance $(\mathrm{F}=6.055 ; p=.001)$; community mental health ideology $(\mathrm{F}=5.598 ; p=.001)$. Also, the significant 
difference was confirmed by measures of central tendencies (mean and standard deviation as displayed in the table 4 . The mean and standard deviation showed that more experienced participants recorded lower score on two CAMI-S subscales (fear and avoidance and community mental health ideology) than other remaining participants groups (group 1: less than year, group 2: 1-3 years, group 3: 4-5 years) recoding highest mean difference results. This mean difference result indicates that more experienced participants reflected less negative attitudes than less experienced participants towards mental illness.

Table 4. Associations between socio-demographic variables and community attitude towards mental illness subscales and the total score and correlations between the level of contact and community attitude towards mental illness subscales and the total score

\begin{tabular}{|c|c|c|c|c|c|}
\hline & & $\begin{array}{l}\text { Open minded and } \\
\text { pro integration }\end{array}$ & $\begin{array}{l}\text { Fear and } \\
\text { avoidance }\end{array}$ & $\begin{array}{l}\text { Community } \\
\text { mental health } \\
\text { ideology }\end{array}$ & Total score \\
\hline \multicolumn{6}{|l|}{ Associations } \\
\hline \multicolumn{6}{|l|}{ Education } \\
\hline \multirow[t]{3}{*}{ Mean } & No primary education & 37.59 & 45.97 & 35.63 & 39.63 \\
\hline & Primary education & 56.29 & 60.08 & 50.35 & 35.92 \\
\hline & Secondary education & 62.25 & 60.75 & 58.00 & 60.75 \\
\hline \multirow[t]{3}{*}{ SD } & No primary education & 12.072 & 13.231 & 14.128 & 10.951 \\
\hline & Primary education & 16.472 & 15.716 & 22.134 & 14.862 \\
\hline & Secondary education & 12.203 & 6.994 & 12.437 & 10.275 \\
\hline $\mathrm{p}$ & & .000 & .000 & .001 & .000 \\
\hline \multicolumn{6}{|l|}{ Experience } \\
\hline \multirow[t]{4}{*}{ Mean } & $>1$ year & 51.15 & 51.31 & 44.41 & 49.49 \\
\hline & $1-3$ years & 52.04 & 53.29 & 38.17 & 48.92 \\
\hline & $4-5$ years & 52.42 & 57.62 & 46.80 & 52.58 \\
\hline & $<5$ years & 53.16 & 56.83 & 47.16 & 59.28 \\
\hline \multirow[t]{4}{*}{ SD } & $>1$ year & 13.716 & 14.194 & 20.474 & 13.050 \\
\hline & $1-3$ years & 16.633 & 16.633 & 17.173 & 15.120 \\
\hline & $4-5$ years & 17.681 & 16.605 & 19.365 & 15.939 \\
\hline & $<5$ years & 22.741 & 16.082 & 21.257 & 17.230 \\
\hline $\mathrm{p}$ & & .974 & .001 & .001 & .057 \\
\hline \multicolumn{6}{|l|}{$\begin{array}{l}\text { Correlation } \\
\text { (dependent } \\
\text { variable: LOC) }\end{array}$} \\
\hline rho & & 023 & -.242 & -.007 & -.066 \\
\hline $\mathrm{p}$ & & .792 & .004 & .937 & .937 \\
\hline
\end{tabular}

A Spearman's rho correlation coefficient was used to test correlation between the participants level of contact and score achieved on the community attitude towards mental illness- Swedish version subscales (subscale 1; open minded and pro integration, subscale 2; fear and avoidance and subscale 3; community mental health ideology); and the total score. Statistically significance was considered if $\mathrm{p}<.05$ and only significant correlation is reported.[25] The spearman's rho correlation coefficient revealed negative correlation ( $\mathrm{rho}=-.242$; $p=.004)$ between participants level of contact and subscale 2 (fear and avoidance). The negative correlation indicates that increases in level of contact correlates with a decrease in score achieved on the fear and avoidance subscale. However, no correlation was found between the level of contact and subscale 1 (open minded and pro integration) and subscale 3 (community mental health ideology) and the total score.

\section{Discussion}

This study revealed negative attitudes among CHWs towards people mentally ill. Participants seemed to agree with the idea emphasising on mental health care being integrated into community-based health care facilities, located in communities. This issue of negative attitudes among CHWs towards persons with mental illness could be a potential obstacle for mental health care integration in health care facilities from the community level to central level. At the same time the community based care relies on CHWs who are involved in preventive, curative and rehabilitation services for any diseases that 
could occur among the community members especially mothers and children. [5,7]

Negative attitude among CHWs will negatively impact maternal health of mothers exposed to develop mental problems particularly before, during and after delivery (perinatal period).

These findings about negative attitude towards people mentally ill are similar to findings from both international and local studies that revealed negative attitudes among the general population and health professionals. For example a study conducted by Barke and colleagues in southern Ghana (2011), revealed negative attitudes towards people mentally ill among urban population. [27] Barke findings were in line with a study conducted (2010) in Nigeria university teaching hospital by Ukpong and colleagues among medical students.[28] In Malesia, a study conducted by Mas and Hatim (2002) revealed stigmatizing attitude among medical students.[29] Similar results were found in a study conducted among South India non-psychiatry medical professionals in an university teaching hospital by Sathyanath and colleagues (2016) reflecting a social restrictive attitude towards persons with mental illness.[30] Negative attitude in regards to mental illness, is not a concern for developing countries only. A study conducted in Sweden by Hogberg and his research team (2008) revealed stigmatizing attitude towards people mentally among the general population. [31]

Also, the current study showed contradictions and neutral positions among CHWs in regards to persons with a mental illness. The neutral and contradictive responses from the participants might be eventually considered as the outcome of social desirability bias. [32,33] This is in line with the United Nations declaration and Rwandan constitution in regards to human rights. The UN declaration and Rwandan constitution emphasize that human beings are equal and must be protected from any form of discriminatory actions.[34,35]

While contradictions and neutral answers were found among the participants, findings from this study showed associations between education level of participants and CAMI- S subscales (open minded and pro integration, fear and avoidance and community mental health ideology) and the total scores. These results are similar to studies conducted by Barke and colleagues in Ghana (2011), Song and colleagues in Taiwan (2005) that revealed association between the level of education and negative attitudes towards people mentally ill.[27,36] Also, association were found between experience of community health workers and subscales 2 (fear and avoidance) and 3 (community mental health ideology). These findings are in line with several local and international studies. For example in the study conducted in western Nigerian in 2007 by Adewaya and Oguntande an association was found between experience and attitude towards people mentally ill.[21] Bjorkman and colleagues (2008) in Sweden, found association between experience and stigmatizing attitude towards persons with mental illness among nursing staff.[37]

Lastly, the current study revealed correlation between the level of contact (LOC) and the subscale 2 (fear and avoidance). These findings are congruent with studies conducted by Corrigan and colleagues (2000) and Holmes and colleagues (1999) suggesting that familiarity with people mentally ill correlates with stigmatizing attitude.[20,24] However, these findings are in contrast with other previous studies conducted by Smith and Middleton in South Africa (2010) and James and colleagues in Southern Nigeria (2012) that revealed no correlation between familiarity and negative attitudes in regards to persons with mental illness. [21,39]

\section{Conclusion}

The study revealed negative attitudes among community health workers in regards to persons with mental illness. Although participants seemed to agree, in principle, that mental health care facilities can, and should be, placed in communities, they also expressed a desire for social distance from persons with mental illness. These contradictions and high levels of neutral responses may suggest that the responses reflected social desirability bias. Level of education and experience of community health workers, were associated with negative attitudes in regards to persons with mental illness. Lastly, familiarity had a mediating effect on negative attitude and may be the foundation for changing attitude within general health care settings.

To clarify the contradictions and neutral position, experimental studies among community health workers are needed to explore the effectiveness of familiarity in reduction of negative attitudes towards people with mental illness among community health workers. Considering the current evidence, it is suggested to the Rwandan Ministry of Health to organize several training sessions to community health workers about mental health. Also, collaboration with the mental health unit in Ruhengeri hospital is highly considered to increase their level of contact with persons with mental illness. Lastly, local authorities should encourage highly educated population (high school and university) to be enrolled among community health workers who are suggested to be highly contributing and involved in the health care system in Rwanda.

\section{Acknowledgement}

First of all, we thank Musanze District to have accepted this research to be conducted among community Health Workers operating in Muhoza health Centre of Ruhengeri hospital in Rwanda. 
Secondarily, we thank the institutional review board/ College of Medicine and Health Sciences which accepted this study to be conducted and granted the ethical clearance.

\section{Conflicts of interest}

No conflict of interest as longer as the study was not funded by any institution or organization. Also, the study was conducted by two researchers who declare no conflict of interest.

\section{Author contributions}

VB participated in conceptual design, empirical analysis and dissemination phases. AG and FU contributed to the analysis and revision of the manuscript.

This article is published open access under the Creative Commons Attribution-NonCommercial NoDerivatives (CC BY-NC-ND4.0). People can copy and redistribute the article only for noncommercial purposes and as long as they give appropriate credit to the authors. They can not distribute any modified material obtained by remixing, transforming or building upon this article. See https://creativecommons.org/ licenses/by-nc-nd/4.0/

\section{References}

1. Association AP. Diagnistic and Statistacal Manuel of Mental Disorder. 5th ed. Washington DC: American Psychiatric Publishing; 2013.

2. World Health Organization. The WHO Mental Atlas 2011. World Heal. Organ. 2011.

3. Mckimm, D, \& Nicholson J. Global health. Rondon: Sage; 2015.

4. World Health Organisation. Comprehensive mental health action plan 2013-2020. Geneva 66th World Heal Assem. 2013;1-27.

5. Rwandan Ministry of Health. National community health policy. Kigali, Rwanda; 2008.

6. Rwandan Ministry of Health. Mental Health Policy in Rwanda. Rwanda; 2011.

7. Rwandan Ministry of Health. Health sector strategic plan 2009-2012. Rwanda; 2009 p. 33.

8. Rwandan Governement. Governance and decentralization joint sector review. Kigali, Rwanda; 2017.

9. Rwandan Governement. Making Decentralized Service Delivery Work: Putting the people at the center of service provision. Kigali; 2006.

10. Kapungwe A, Cooper S, Mayeya J, Mwanza J, Mwape L, Sikwese A, et al. Attitudes of primary health care providers towards people with mental illness: evidence from two districts in Zambia. Afr J Psychiatry. 2011;14.

11. Ssebunnya J, Kigozi F, Kizza D, Ndyanabangi S. Integration of Mental Health into Primary Health Care in a rural district in Uganda. Afr J Psychiatry. 2010;13:128-31.

12. Mwape L, Sikwese A, Kapungwe A, Mwanza J, Flisher A, Lund C, et al. Integrating mental health into primary health care in Zambia: A care provider's perspective. Int J Ment Health Syst. 2010;4.

13. Corrigan PW, Powell KJ, Fokuo JK, Kosyluk KA. Does humor influence the stigma of mental illnesses? J Nerv Ment Dis. 2014;202:397-401.

14. Rosenberg S.J. \& Rosenberg. J. Community mental health: Challenges for the 21st Century. 3rd ed. Rondon: Routledge; 2018.

15. Vedaste B. Students Nurses stigmatizing attitudes towards persons with a mental disorder in a selected school of nursing in Rwanda. Rwanda J Med Heal Sci. 2017;4:1-7.

16. Vedaste B, Smith AAH. 'In principle, yes, in application, no': Rwandan nurses' support for integration of mental health services. African J Nurs Midwifery. 2016;18:170-82.

17. Polit, D F, \& Beck CT. Nursing research: Generating and Assessing Evidence for Nursing Practice. 9th ed. Philadelphia: Wolters Kluwer Health/ Lippincott Williams and Wilkins; 2012.

18. World Health Organization. 19th WHO Model list of medicines. Geneve; 2015.

19. Corrigan PW, Edwards AB, Green A, Diwan SL, Penn DL. Prejudice, Social Distance, and Familiarity with Mental Illness. Schizophr Bull. 2001;27:219-25.

20. James BO, Omoaregba JO, Okogbenin EO. Stigmatising attitudes towards persons with mental illness: A survey of medical students and interns from Southern Nigeria. Ment Illn. 2012;4:32-4.

21. Adewayu, A O, \& Maknjuola ROA. No TitleLay belief regarding causes of mental illness in Nigeria, pattern and correlates. Soc Psychiatry Psychiatr Epidemiol. 2008;43:336-41.

22. Mårtensson G, Jacobsson JW, Engström M. Mental health nursing staff's attitudes towards mental illness: An analysis of related factors. J Psychiatr Ment Health Nurs. 2014;21:782-8.

23. Holmes EP, Corrigan PW, Williams P, Canar J, Kubiak MA. Changing attitudes about schizophrenia. Schizophr Bull. 1999;25:447-56. 
24. Hogberg T, Magnusson A, Ewertzon M, Lutzen $\mathrm{K}$. Attitudes towards mental illness in Sweden: adaptation and development of the Community Attitudes towards Mental Illness questionnaire. Int J Ment Health Nurs. 2008;17:302-10.

25. Pallant I. SPSS survival manual. 5th ed. Berkshire, England: Open University Publishers.; 2013.

26. Maree K. First steps in Research. 1st ed. Pretoria: Van Schaik.; 2008.

27. Barke A, Nyarko S, Klecha D. The stigma of mental illness in Southern Ghana: Attitudes of the urban population and patients' views. Soc Psychiatry Psychiatr Epidemiol. 2011;46:1191-202.

28. Ukpong DI, Bs MB. articles Stigmatising attitudes towards the mentally ill: A survey in a Nigerian university teaching hospital. Sajp. 2010;16:56-60.

29. Mas A, Hatim A. Stigma in mental illness: attitudes of medical students towards mental illness. Med J Malaysia. 2002;57:433-44.

30. Sathyanath S, Mendonsa RD, Thattil AM, Chandran VM, Karkal RS. Socially restrictive attitudes towards people with mental illness among the nonpsychiatry medical professionals in a university teaching hospital in South India. Int J Soc Psychiatry. 2016;62:221-6.

31. Högberg T, Magnusson A, Ewertzon M, Lützén K. Attitudes towards mental illness in Sweden: Adaptation and development of the community attitudes towards mental illness questionnaire. Int J Ment Health Nurs. 2008;17:302-10.
32. Putman S. Mental illness: Diagnostic title or derogatory term? (Attitudes towards mental illness) Developing a learning resource for use within a clinical call centre.A systematic literature review on attitudes towards mental illness. J Psychiatr Ment Health Nurs. 2008;15:684-93.

33. Kopera M, Suszek H, Bonar E, Myszka M, Gmaj $\mathrm{B}$, Ilgen $\mathrm{M}$, et al. Evaluating Explicit and Implicit Stigma of Mental Illness in Mental Health Professionals and Medical Students. Community Ment Health J. 2015;51:628-34.

34. United Nations. Universal Declaration of Human Rights. USA; 1995.

35. Republic of Rwanda. Constitution of Rwanda. Rwanda; 2016.

36. Song, L, Chang, L, Yi, C, Shih, Yuan, C, Lin \& Y. No TitleCommunity attitudes towards the mentally ill: The results of a national survey of the taiwanese population. Int J Soc Psychiatry. 2005;51:174-88.

37. Björkman T, Angelman T, Jönsson M. Attitudes towards people with mental illness: a cross-sectional study among nursing staff in psychiatric and somatic care. Scand J Caring Sci. 2008;22:170-7. 